\title{
Modelling maximum discharge of the catastrophic flood at the lya River (Irkutsk region, Russia) in 2019
}

\author{
Alexandra Fedorova ${ }^{1 *}$, Olga Makarieva ${ }^{1,2}$, Nataliia Nesterova $^{1,3}$, Andrey Shikhov ${ }^{4}$, and \\ Tatyana Vinogradova ${ }^{1}$ \\ ${ }^{1}$ Saint-Petersburg State University, 199034 Saint-Petersburg, Russia \\ ${ }^{2}$ Melnikov Permafrost Institute, 677010 Yakutsk, Russia \\ ${ }^{3}$ State Hydrological Institute, 199053 Saint-Petersburg, Russia \\ ${ }^{4}$ Perm State University, 614990 Perm, Russia
}

\begin{abstract}
The aim of the study is to estimate the maximum discharge of the catastrophic flood in June 2019 at the Iya River (Irkutsk Region, Russia). The main cause of this flood was extreme precipitation (170 mm for 3 days). The distributed deterministic hydrological model Hydrograph was applied. The schematization of the Iya river basin, parametrization and verification of the Hydrograph model were performed. The median value of the Nash-Sutcliff criteria was 0.69 for the period 1970-1996 for three catchments of the Iya River basin. Based on the data of weather stations and global weather forecast model ICON, maximum daily discharge values of the flood were estimated as 6570 and $4780 \mathrm{~m}^{3} \mathrm{~s}^{-1}$ respectively with the possible value range assessed by the dependence of $\mathrm{Q}(\mathrm{H}) 6250-7500 \mathrm{~m}^{3} \mathrm{~s}^{-1}$. The flood hydrograph estimated from weather station data coincides in magnitude of flood peak, but its formation is delayed by 1 day. ICON data underestimates maximum value but provides proper timing of the flood peak. The ensemble of input meteorological data from various sources could potentially be used to satisfactorily predict the magnitude and duration of the catastrophic flood and minimize the consequences of the flood.
\end{abstract}

\section{Introduction}

Irkutsk Region, located in the South-Eastern part of Siberia (Russia), regularly experiences flooding caused by extreme precipitations. Earlier, such floods in this area occurred in 1984, 1996, 2001 [1].

The most hazardous flood was observed at the rivers originating from the Eastern Sayan mountains in June 2019. As a result of the flood, 107 settlements were affected, 25 people died and 8 were missing [2]. According to preliminary assessment, economic damage from the flood in 2019 amounted up to half a billion Euro in Irkutsk region [3]. The main reasons of hazardous flood discussed in the media are melting of snow and glaciers in the mountains, deforestation and forest fires, heavy, long rains as a result of climate change [4].

\footnotetext{
* Corresponding author: alexandra120559@gmail.com
} 
The assessment of design flood characteristics in Russia is based on a historical observed data. But the issues related to the questionable applicability of historical observed data to assess hydrological characteristics at present are widely discussed $[5,6]$. The necessity for development of new methods for assessment, including the methods based on mathematical modeling of flow formation processes is manifested [7, 8]. Due to the increase in the frequency and amplitude of extreme hydrological events in the future [9], it is necessary to develop new methods for calculating and predicting hydrological characteristics that can take into account the recent and future changes.

The aim of the study is to estimate the maximum discharge of the catastrophic flood in June 2019 at the Iya River at the Irkutsk Region (Russia) based on hydrological modelling approach and assess other possible reasons which could cause the flood.

\section{Study area}

The Iya River basin $\left(14500 \mathrm{~m}^{2}\right)$ (the South-Eastern part of Siberia, Russia) belongs to the zone of dark coniferous taiga (Fig. 1). The Iya River originates from the northern slopes of the Eastern Sayan up to $2789 \mathrm{~m}$ of altitude (the Holba peak). The study area is divided into mountain and lowland. There are significant areas occupied by goltsy in the mountain part. The area has a continental climate. Affected by both climate and terrain, the rainfall distribution in space and time is uneven. The annual precipitation in different parts of the basin changes from $350 \mathrm{~mm} \mathrm{yr}^{-1}$ to $760 \mathrm{~mm} \mathrm{yr}^{-1}$. The main amount of precipitation falls in the summer period.

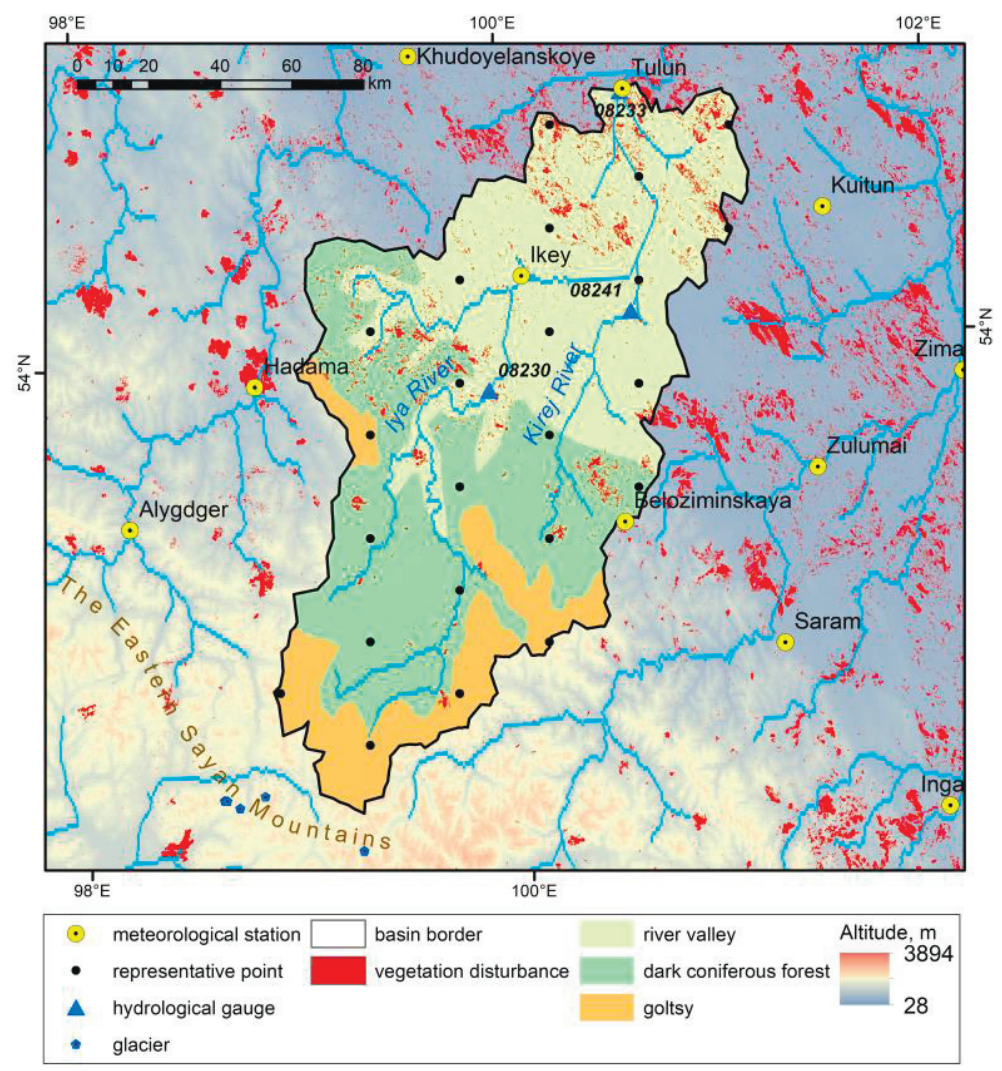

Fig. 1. The scheme of the Iya River basin at Tulun. 
The hydrological regime of the Iya River is characterized by spring-summer flood, high summer rainfall floods and a low winter flow. The main part of runoff is formed in mountain (56\% of the total area) and reaches about $280 \mathrm{~mm} \mathrm{yr}^{-1}$. On the lowland, about 50 $\mathrm{mm} \mathrm{yr}^{-1}$ is formed. There are three hydrological gauges where streamflow measurements are conducted in the Iya River basin (Table).

\section{Verification of hydrological model}

Distributed process-based hydrological model Hydrograph is used in this study. It describes all components of the land hydrological cycle, including precipitation and its interception; snow accumulation and melting; evaporation from snow, soil, and vegetation cover; surface flow and infiltration; soil water dynamics and flow; heat dynamics and phase change in soil layers; underground flow formation, slope and channel flow transformation $[10,11]$. The model is a workable tool for studying hydrological processes and assessing the characteristics of runoff under various physical and geographical conditions and on objects of any size from the soil column or elementary slope to large river basins without changing the structure and algorithms. The description of the model and methods for its parameterization are presented in detail in earlier studies [10-15].

The input to the model is a limited set of meteorological forcing data (air temperature and humidity, precipitation) that can be obtained for most of the weather stations. The main output includes streamflow, water balance components and variable states (snow depth, soil moisture, temperature and other).

The basin of the Iya River was divided into three runoff formation complexes (RFC) based on satellite imagery Landsat- 8 and the landscape map of the USSR: goltsy, dark coniferous forest and river valleys (Fig.1). RFC - are the areas which can be described by one set of the model parameters presenting some kind of hydrological landscapes where runoff formation processes are taken as uniform. Parameters of this RFC (vegetation and soil cover, surface) were determined based on reference materials (observed data under identical climatic conditions). The catchment was also covered with a regular grid of representative points (RP). The hydrological processes are simulated at RPs that possess the unique topography characteristics and the set of the model parameters related to one of the RFCs.

We used daily meteorological data, such as air temperature, air moisture, and precipitation from 7 weather stations (Fig. 1) to simulate streamflow for verification of the hydrological model. The station Beloziminskaya $(755 \mathrm{~m})$, which is the most representative for the mountainous part of the catchment, was ceased after 1996. The modelling period (1970-1996) was determined by the availability of data for all weather stations. The interpolation of precipitation was carried out taking into account the distribution of snow and rainfall in the mountains.

Runoff formation processes were simulated for the subbasins of the Iya River basin (Table) with a daily time step for the model verification. The median value of the NashSutcliff criteria was from 0.66 to 0.72 for the period $1970-1996$ for three catchments (Table $1)$. The difference in the mean annual value of the calculated and observed flow does not exceed $7 \%$. In addition, we verified the model by maximum water discharges. The curves at Fig. 2 show the exceedance probability of calculated and observed annual maximum water discharge for the simulation period 1970-1996 at the Iya River basin at Tulun. The difference in values does not exceed $300 \mathrm{~m}^{3} \mathrm{~s}^{-1}(8 \%)$. The results have been considered satisfactory, and the Hydrograph model being suitable for modelling the processes of runoff formation in the territory under consideration. 
Table. Characteristics of runoff gauge stations, water balance and efficient criteria, 1970-1996.

\begin{tabular}{|c|c|c|c|c|c|c|c|c|c|}
\hline Index & $\begin{array}{c}\text { River }- \\
\text { gauge }\end{array}$ & Period & $\mathrm{S}\left(\mathrm{km}^{2}\right)$ & $\mathrm{H}(\mathrm{m})$ & Yo & Ys & $\mathrm{P}$ & $\mathrm{E}$ & NS (m/av) \\
\hline 8230 & $\begin{array}{c}\text { Iya }- \\
\text { Arshan }\end{array}$ & $\begin{array}{c}1963- \\
2017\end{array}$ & 5140 & 1483 & 540 & 528 & 771 & 243 & $0,69 / 0,62$ \\
\hline 8233 & $\begin{array}{c}\text { Iya }- \\
\text { Tulun }\end{array}$ & $\begin{array}{c}1941- \\
2017\end{array}$ & 14500 & 979 & 326 & 338 & 586 & 247 & $0,72 / 0,67$ \\
\hline 8241 & $\begin{array}{c}\text { Kirej- } \\
\text { Ujgat }\end{array}$ & $\begin{array}{c}1959- \\
2017\end{array}$ & 2950 & 873 & 374 & 402 & 688 & 286 & $0,66 / 0,57$ \\
\hline
\end{tabular}

Note: $\mathrm{S}$ - basin area, $\mathrm{km}^{2} ; \mathrm{H}$ - average catchment elevation (m); Yo and $\mathrm{Ys}$ - observed and calculated mean annual streamflow, mm; P, E - calculated precipitation and evaporation, $\mathrm{mm}$; $\mathrm{m}$ and av median and average value of Nash-Sutcliffe (NS) criteria.

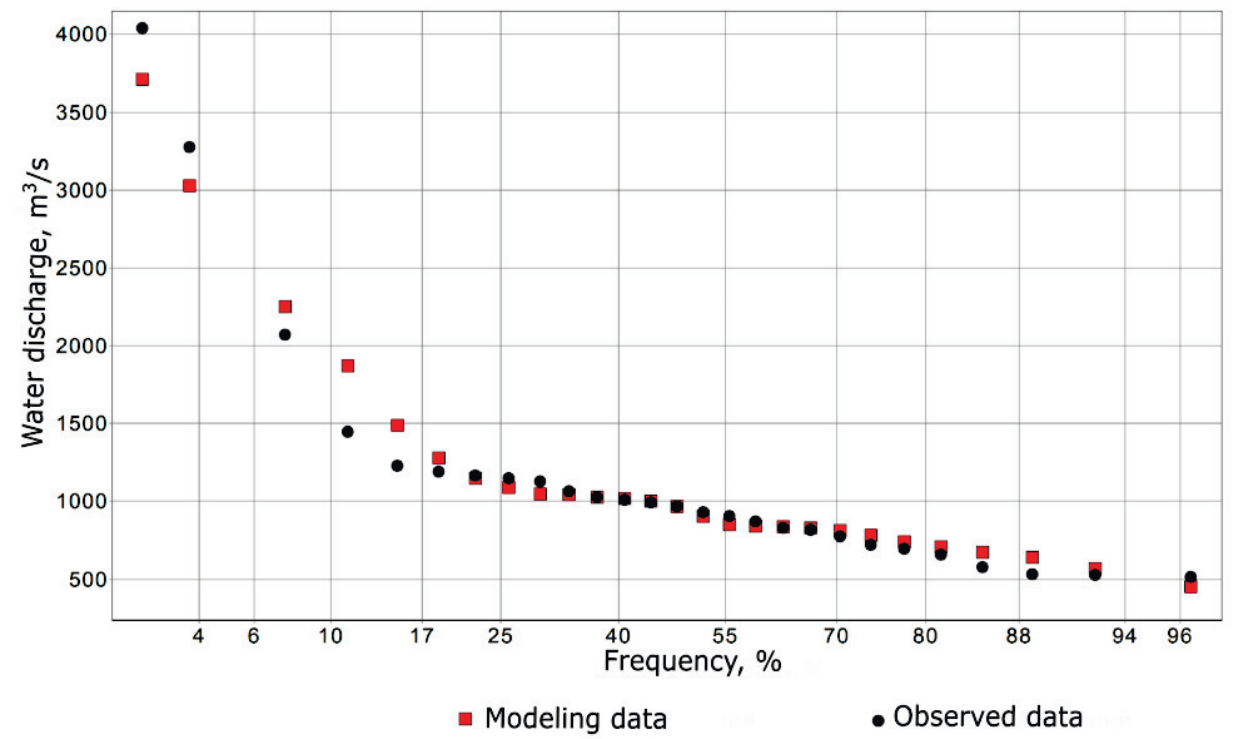

Fig. 2. The curves of frequency of maximum water discharge according to modeling results (red points) and the observations (black points), the Iya river - Tulun, 1970-1996

\section{Assessment of the hazardous flood causes}

We have analyzed satellite image Landsat- 8 for June 23 which shows that even in the mountainous part of the basin less than $10 \%$ of the area was covered with snow at that time. This could not cause flooding of such magnitude. Deforestation also could not be the reason of this flood because the deforested area in the basin occupies less than $4 \%$ of the total catchment area (Fig. 1) [16].

The analysis of changes in hydrometeorological characteristics by the Mann-Kendall method with a significance level $p<0.05$ and the Tain-Sen method to assess the magnitude of trends for the period 1966-2019 were carried out. The air temperature over the indicated period increased by 1.2 $-2.1{ }^{\circ} \mathrm{C}$; there is an increase of rainfall in June by $36-61 \%$ or $31-46 \mathrm{~mm}$. Increase of streamflow is observed only in the cold period, from November to April. The series of maximum daily streamflow for the gauge the Iya River - Tulun is characterized by a negative trend (on average $37 \%$ in May and July at $\mathrm{p}<0.05$ and $24 \%$ in June and August at $\mathrm{p}<0.08$ ). 


\section{Simulations of maximum discharge based on different sources of meteorological data}

Two experiments with different types of input meteorological data due to the lack of representative observational data were conducted to simulate the hazardous flood in June 2019. We used 1) the daily meteorological data from two stations (Ikey and Tulun) and 2) the data from the global weather forecast model ICON [17] as the input. Both types of data were available only for the period of 1-30 June, therefore the year 1989 was adopted as the initial conditions for running the hydrological model. In 1989 the spring flood conditions by magnitude and timing were similar to the conditions of 2019.

Using the weather stations data the following distribution of water balance was obtained based on simulations: basin precipitation during 25-27 June - $239 \mathrm{~mm}$, including $79 \mathrm{~mm}-$ on June $25,132 \mathrm{~mm}$ - on June $26,28 \mathrm{~mm}$ - on June 27. The estimated maximum daily discharge reaches $6570 \mathrm{~m}^{3} \mathrm{~s}^{-1}$ (Fig. 3).

For the $2^{\text {nd }}$ types of input (ICON model data) we used daily data for 1989 until May 31 and 3-hour ICON data from June 1 to 30. Total basin precipitation amounted to $170 \mathrm{~mm}$ during 25-27 June. As a result, the maximum calculated 3-hour discharge reached 5260 $\mathrm{m}^{3} \mathrm{~s}^{-1}$, maximum daily value was $4780 \mathrm{~m}^{3} \mathrm{~s}^{-1}$ (Fig. 3).

Using water level $(\mathrm{H})$ and discharge $(\mathrm{Q})$ historical data we estimated possible discharge based on the curve $\mathrm{Q}(\mathrm{H})$. The possible value is within the range from 6250 to $7500 \mathrm{~m}^{3} \mathrm{~s}^{-1}$ (blue area in Fig. 3.).

The maximum discharge based on ICON data is $1400 \mathrm{~m}^{3} \mathrm{~s}^{-1}$ lower than the observed, however, its formation coincides by timing. According to weather station data, the maximum discharge coincides in magnitude, but its formation is delayed by 1 day.

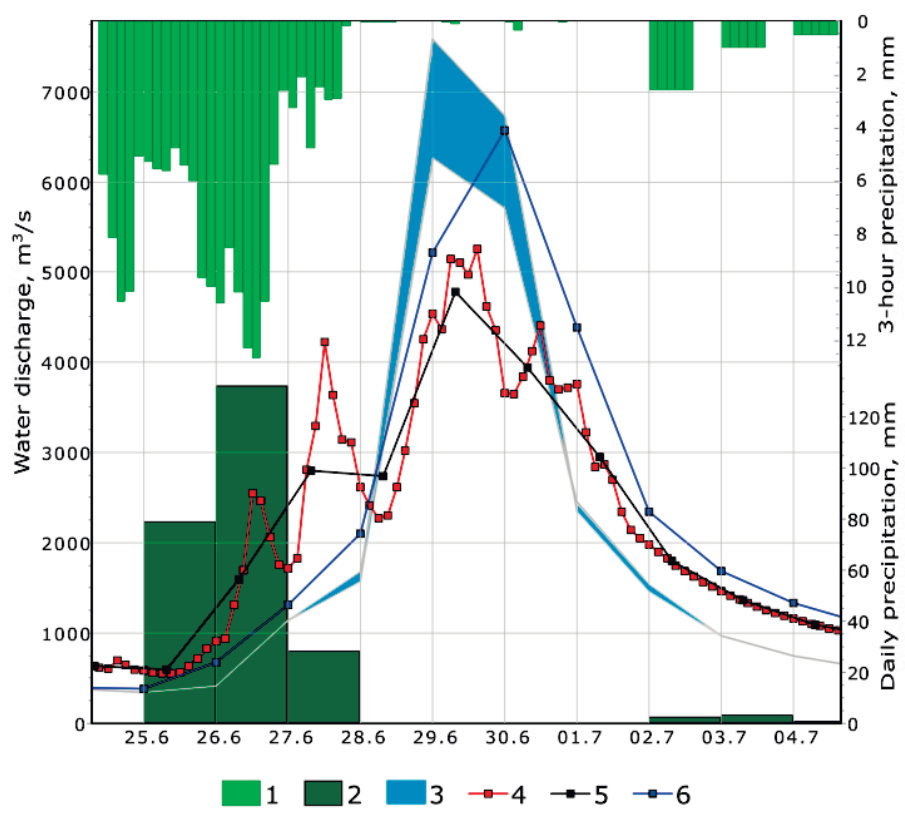

Fig. 3. The results of flood modeling at the Iya River - Tulun in June 2019: 1, 2 - the amount of precipitation for the catchment - 3-hour precipitation according to the ICON weather model and daily precipitation based on data from weather stations; 3 - the observed flow hydrograph (based on extrapolation of the dependence of water flow on the level); 4, 5 - calculated 3-hour and averaged daily flow hydrograph according to the ICON weather model; 6 - calculated daily runoff hydrograph based on data from weather stations. 


\section{Conclusions}

In this study, precipitation as the main reason for the catastrophic flood at the Iya River in 2019 is revealed. Based on the weather station and weather model data, maximum daily discharge values were estimated as 6570 and $4780 \mathrm{~m}^{3} \mathrm{~s}^{-1}$ respectively with the possible value range assessed by the dependence $\mathrm{Q}(\mathrm{H}) 6250-7500 \mathrm{~m}^{3} \mathrm{~s}^{-1}$.

By the study we also attempted to show the need to expand the meteorological and hydrological network in the region. We also demonstrate the capabilities of the modern calculation methods and forecasts in case of insufficient observed data. In our opinion, the ensemble of input meteorological data from various sources could potentially be used to satisfactorily predict the magnitude and duration of the catastrophic flood. So, the results of the study confirm the fundamental possibility of a short-term flood forecast, using the method of deterministic hydrological modeling.

In the subject of the climate changes assessment this study was supported by the Russian Foundation for Basic Research, project no. 19-55-80028.

\section{References}

1. N.V. Kichigina, Geography and Natural Resources, 2 (2018).

2. Information agency of Russia, 2019. URL: https://ria.ru/20190721/1556733218.html (accessed: 22.07.2019). (in Russian)

3. Official website of the publishing house Kommersant, URL:

https://www.kommersant.ru/doc/4019553 (accessed: 22.07.2019). (in Russian)

4. Official website of the information and analytical publication « Tajga.info - Glavnye novosti Sibiri» URL: https://tayga.info/147658 (accessed: 18.07.2019). (in Russian)

5. J. Shaleen, L. Upmanu, Water Resources Research, 37, 12 (2001).

6. J. R. Stedinger, V. W. Griffis, Journal of Hydrologic Engineering, 13, 4 (2008).

7. D. Cameron, K. Beven, P. Naden, Hydrology and Earth System Sciences Discussions, 4, 3 (2000).

8. O. Seidou, A. Ramsay, I. Nistor, Natural Hazards, 61, 2 (2011).

9. P. C. D. Milly, R. T. Wetherald, K. A. Dunne, T. L. Delworth, Nature, 415 (2002).

10. Yu. B. Vinogradov, Gidrometeoizdat (1988).

11. Yu.B. Vinogradov, O.M. Semenova, and T.A. Vinogradova, Hydrol Process, 25, $1055-1073(2011)$

12. O. M. Makarieva, N. V. Nesterova, T. A. Vinogradova, I. N. Beldiman, A. D. Kolupaeva, Vestnik of Saint Petersburg University. Earth Sciences, 64, 1 (2019).

13. O. M. Makarieva, T. A. Vinogradova, N. V. Nesterova, A. Y. Vinogradov, I. N. Beldiman, A. D. Kolupaeva, Georisk, 12, 3 (2018).

14. O. Semenova, L. Lebedeva, N. Volkova, I. Korenev, M. Forkel, J. Eberle, M. Urban, Hydrol Sci J. 60, Issue 7-8, 1225-1241 (2015)

15. O. Semenova, L. Lebedeva, Yu. Vinogradov, Hydrogeol J. 21(1), 107-119 (2013)

16. Published by Hansen, Potapov, Moore, Hancher et al. Global Forest Change. URL: https://earthenginepartners.appspot.com/science-2013-global-forest (accessed: 20.07.2019)

17. G. Zängl, D. Reinert, P. Rípodas, M. Baldauf, Quarterly Journal of the Royal Meteorological Society, 141 (687), 563-579 (2015) 